\title{
READING AS CULTURAL CAPITAL AND SOCIAL INTERACTION
}

\author{
Audronè Lapienienė \\ Natalija Mažeikienè \\ Vytautas Magnus University, Lithuania
}

\begin{abstract}
The article focuses on the social aspects of reading. Conceptual framework of cultural capital is usedin order to actualise the importance of sociocultural and socioeconomic factors in family and at school for the child's reading. The research reveals complex and multifaceted development of children's reading skills: different factors such as cultural environment, cultural activity, and cultural objects in family and at school (in the classroom and library) interact and increase the possibilities for the child to acquire and integrate social knowledge. Aim of the researchis to analyse the interplay between educational and social factors during formation of reading in pupils. The following objectives have been set out to reach this aim: 1) to perform literature review of reading as social interaction and cultural capital, social factors determining reading in children; 2) to reveal the interplay between educational and social factors during formation of the children's reading habitus by conducting interviews with the expert focus group.Methods of the research:group interviews with 24 experts of reading - primary school teachers, authors of textbooks of Lithuanian language and reading comprehension for primary schools, publishers of textbooks for primary schools were conducted.
\end{abstract}

Keywords: Bourdieu, cultural capital, reading, reading environment, reading skills, social interaction.

\section{Introduction}

Obvious decline in reading among children has started raising concerns recently. Globalisation and IT processes have caused changes of the society and economic structures. Viewing the decline in reading as a mere educational process would obviously be too narrow in the context of the dramatic macro processes. Reading is determined not only by educational, but also social, cultural, and economic factors. The main focus of this article is put on the social aspects of reading. As the determinants of child's reading abilities, social factors attract attention of many researchers(Bourdieu, 1990; Rudell, 2005; Sullivan, 2001, and others). Explanation of the reading phenomenon from the sociological perspective helps not only reveal the social factors that influence reading skills, but also analyse reading as a certain form of social interaction and cultural capital more comprehensively. P.Bourdieu (1986) has noted that an individual accumulates cultural capital in three states: embodied state (cultural activity), objectified state (possessing cultural goods and objects), and institutionalised state (education). Sociological approach views reading as a practice and suggests that reading abilities could be analysed as an expression of cultural 
capital. This article analyses two states of cultural capital: cultural reading activity (embodied state) is analysed along with cultural resources possessed by family and school (objectified cultural capital), in this case, books and reading material.

Researchers J. Katsillis and R. Rubinson (1990) have revealed certain inter play between such cultural forms as visiting of theatres, galleries, exhibitions, and book reading and children's reading and learning achievements. J. J. Walczykand, D. A. Griffith-Ross (2007), who have analysed the importance of social factors for (self-) formation of a child's cultural capital, have argued that the importance of these factors depends on the sociocultural environment in the family and at school. The importance of cultural and educational environment for children's learning achievements and their reading abilities has been emphasized by D. Rudells (2005).Cultural resources of the family have considerable effect on the child's personality (Sullivan, 2001).

The aim of this article is to discuss and analyse the interplay between educational and social factors during formation of reading in pupils. The following objectives have been set out to reach this aim: 1) to perform the analysis of scientific literature on reading as social interaction and cultural capital, social factors determining reading in children; 2) to reveal the interplay between educational and social factors during formation of the children's reading habitus by conducting the analysis of the interview with the expert focus group. The article presents the results of empirical study. The qualitative study was conducted in 2009 and involved 24 experts of reading: primary school teachers, authors of Lithuanian language textbooks and reading textbooks for primary schools, publishers of textbooks.

\section{Reading as social interaction}

When reading is explained as social interaction, symbolic nature of such interaction is emphasized (Blumer, 1969). Interaction through symbols takes place during reading by passing and accepting the meanings and symbols. Individuals pass the meanings through symbols to other participants of the process of social interaction during the process, and the participants interpret the symbols and respond to them by exploring their meanings. An actor who takes in the information, primarily accepts the symbols and roles that he/she recognizes the best. In the course of interaction, an actor interacts not only with other participants of the interaction, but also with oneself. Acting individuals become engaged in the social action and, in their thoughts, interact not only with oneself, but also with another participant of the same social action (Leonavičius, 2005). A social actor "sorts, arranges, puts aside, regroups" the encountered symbols and "rearranges their meanings according to the current situation". Therefore, interpretation should not be viewed as mechanical application of meanings, given that meanings are used during interpretation as tools that shape the action determined by the acting individuals (Blumer, 1969). As 
interpretation of an action forms the basis of the interaction of symbols, an actor's thinking abilities are formed by the actor while he/she passes and accepts the symbols, and the ability of revealing and interpreting the encountered cultural and social symbols is implemented (Leonavičius, 2005).

Analysis of reading as a social action and application of the idea of social interaction to reading become centred on the reader, who is one of the actors of social interaction. Another actor of the act of reading is the author of the text. These two types of social actors - author and reader of the text - imply reading as a form of interaction, when text becomes the mediator of interaction by symbols. Although an individual seems to create the relationship with the text, the text is amediator between the reader and the writer. A text leads its reader to create own world as a result of interpretation of the meaning, which means that the interaction between the author and reader in the social field involves integration of different cultural worlds, their forms of arrangement and transformation of the individual's thoughts and perception. Having received information, an individual may direct it towards the cognition that he/she needs. Reading is an obvious tool of experiences, knowledge, and learning. Social interaction allows an individual expand his/her social and cultural field of cognition. Process chart has been developed based on the insights expressed by the article authors, involving the participants of social interaction and their mutual relations (see Fig.1). It must be noted that the participants of interaction are important each individually, as well as collectively.

\section{Helps interpretDecodesCodes}

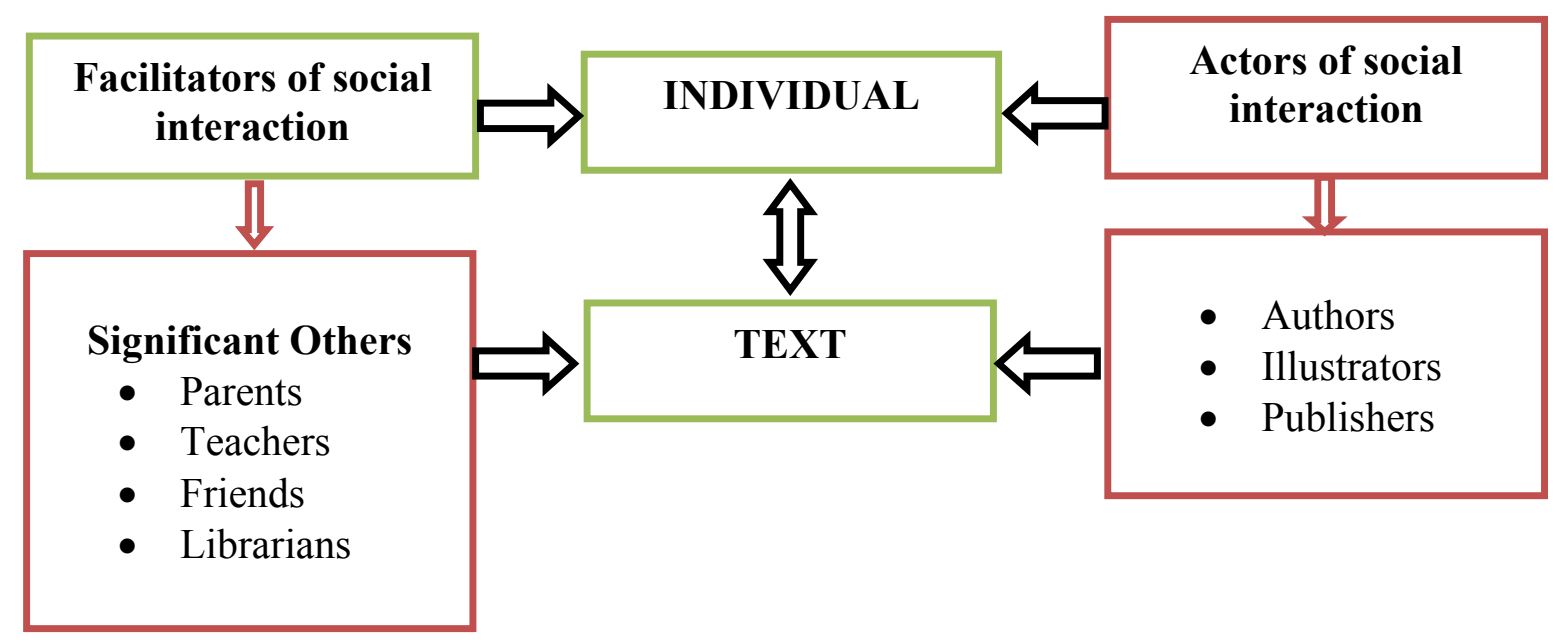

Figure 1. Process of reading as social interaction and its participants

Regardless of the nature, place, or time of reading, the reader empowers the interaction with the text author. He/she interprets the meanings created and written down by the author or illustrator, while the process of transfer and acceptance of information happening during reading forms individual models of meaning that are based on the mechanism of mutual interaction with other 
participants of the activity of transfer of meanings. However, if the reader is a child, the role of participants of information is stronger and the circle of participants is wider, involving the illustrator, teacher, parents, and librarians, besides the writer. If the child does not read by himself/herself, he/she listens to the person reading, e.g. a family member, teacher, peer, or librarian.

In terms of text reading during the learning process, the notion of a text author (e.g. textbook, teaching aid), is also broader. Here, a textbook or teaching aid text author is not a person who has written the text - the authorship, in a broader sense, besides the author, should be attributed to reviewers, illustrators, editors, etc. Illustrators introduce a unique visual symbolism into the context.

Child's social context of reading experience is formed by other significant participants of the interaction who empower the reading process by creating the appropriate environment (see Fig. 2.).

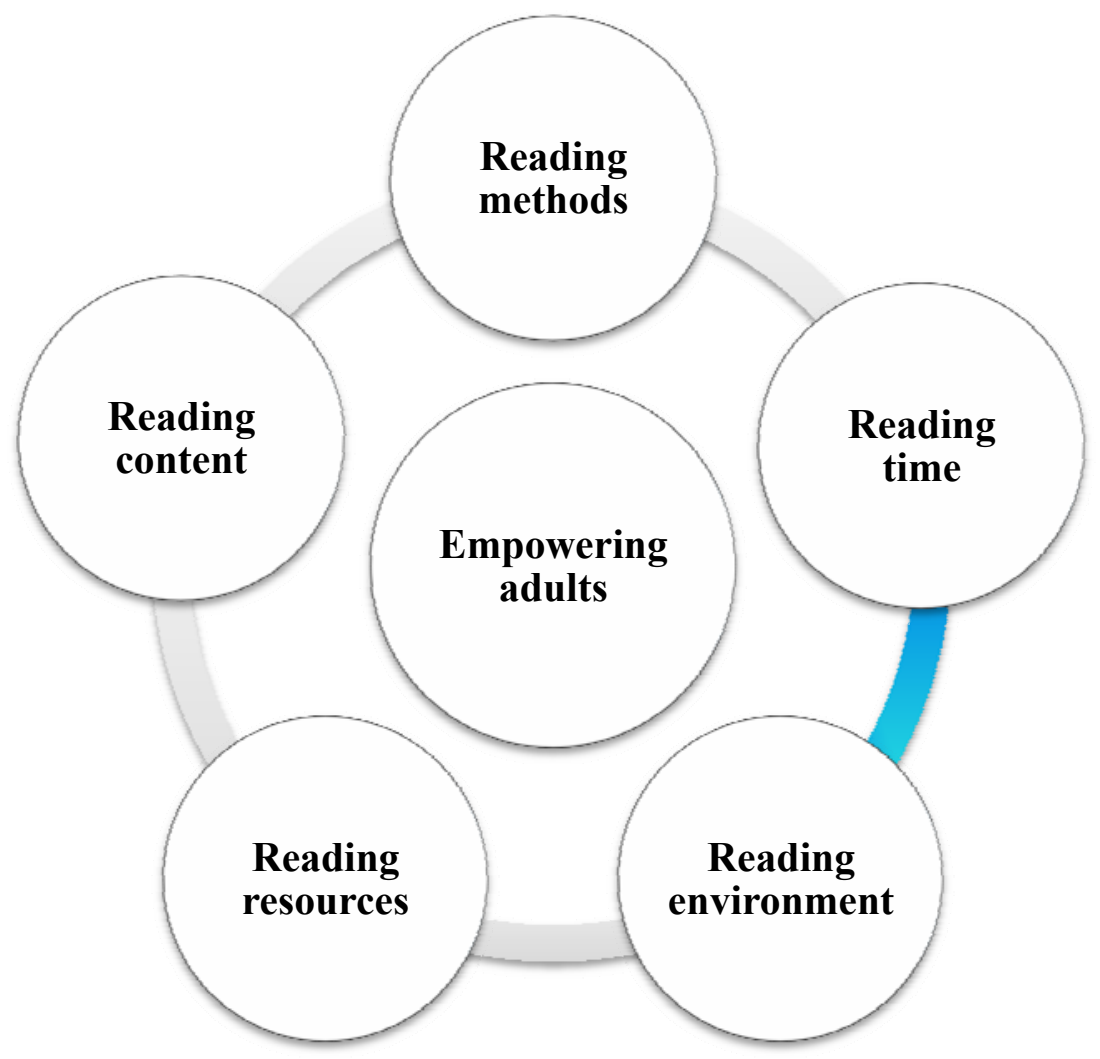

Figure 2. Social context of reading

The context of reading is created by the empowering adults or significant others (parents, teachers, friends, librarians). They sort and collect reading material, form home, school, classroom library and the content of publications in the library material, organise a number of different and attractive reading activities for children, and perform, to a certain extent, management of the child's interaction with the text. Burgess has identified two groups of parents' activity with a child: passive and active. Passive activity is the activity, when a 
child sees his/her parents read or watch television. Active activity is the activity, when parents read with the child (Burgess, 2002).

Child's first reading space is home reading space formed of the home library, the number and content of books comprising it (adults' books, adolescents' books, and children's books), attitudes towards reading, forms of reading, and reading itself. P. Bourdieu (1990) has suggested that the content of home library reflects the family's reading tastes, professionalism, level of literary development of the family, amateur interests of different generations, and prioritisation of books in childhood. A child's as a reader life is constructed by day to day reading activity. Family reading environment becomes a mediator between cultural objects and cultural activity (Bourdieu, 1990). It is the family's cultural environment that shapes the prospective reader.

Researchers studying cultural capital emphasize that an individual's knowledge, cultural and social skills pass to his/her cultural capital (Bourdieu and Passeron, 1990). Cultural capital is concentrated on the person's abilities, knowledge, beliefs and values, and is based on linguistic and cultural competences. Bourdieu has ascribed an exceptional role to the cultural capital: cultural capital is not only knowledge and learning achievements, education and linguistic skills, but also consumption, perception of cultural forms and their application to social interaction, lifestyle, and cultural reproduction. According to P. Bourdieu, reading may be analysed as an expression of cultural capital, as reading activities and resources necessary for reading (books, prints) are reproduced into the child's knowledge and abilities.

Analysis of these links has demonstrated that more pronounced reading abilities in children may be predicted by looking at the specific conditions of education in family that are revealed by the parents' education, number of books available at home, and reading and writing skills acquired during the preprimary school period.

\section{Method}

The role of textbooks (Lithuanian language) for primary education at schools in Lithuania was identified as a main focus of the research. For this purpose, interviews with Lithuanian reading experts - primary school teachers, authors of textbooks of Lithuanian language and reading comprehension for primary schools, publishers of textbooks for primary schools - were conducted. Discussions took place on the content of textbooks, fiction and non-fiction (informative) text, extra reading together with social actors (teachers, parents, librarians).

The method of group interview (semi-structured expert interview) was used in the study to reveal the context and prospects of perception of reading as social interaction. The method of group interview (semi-structured expert interview) was used in the study to reveal the context and prospects of perception of reading as social interaction. Its benefit lies in that it helps reveal the research 
participants' experiences and presents the possibility to encourage them to share own knowledge by asking questions. As the researcher needed professional expertise and knowledge on the studied problem, experts were chosen as research participants due to their characteristic feature - competence and knowledge on own experience related to a certain issue (Uwe Flick, 2014, p. 227).

The study was conducted in November-December, 2009. The total of three interviews with focus groups of experts was conducted. The interviews were held in Kaunas and Vilnius. The first interview was held in November in Kaunas, and involved 11 experts. The second interview in November in Vilnius was attended by 8 experts. The third interview with 5 experts took place in December in Vilnius. Duration of each interview was 2 to 2.5 hours. The study (expert interview, focus group interviews) was aimed at revealing the experts' attitudes towards the situation of reading abilities in children of primary school age (7-11 years old): reading teaching aids, reading environments at school and in classroom, parents and teachers' relations in development of reading abilities in children. Data analysis of the study has been conducted by classification and interpretation. Categories and subcategories have been identified, and quotations from the interviews and the researcher's insights have been presented.

\section{Research results}

Reading at school. Reading resources comprised of teaching and extracurricular reading materials are important for development of reading abilities in a child. Experts have indicated that Lithuanian language textbooks and reading textbooks are the main tools used for development of reading at school.

The experts have noted that although reading resources play special role at school in development of children's reading skills, this area has been highly neglected. School library is a very important milieu of reading. However, libraries are dominated by textbooks and teaching aids, while the necessary fiction and informative literature is almost absent, as "schools order basic textbooks only, and do not purchase any extra material", according to one expert (teacher 1). $10)$.

We suggest books to read, but they are absent from the libraries (teacher

School library is very important, but all of this is completely obsolete in Lithuania. If a child is given a task during the lesson, he should go to the library with the sheet of paper to take the book and work independently" (textbook author 1).

Moreover, the experts have emphasized that although a librarian also performs an important role in development of reading, there is shortage of professional librarians at school to assist children during the process of reading.

Librarian's work with a child should be a part of the lesson (teacher 3). 
The role of classroom library and activities in classroom. The experts have identified teacher's personal interest as the most important factor - a teacher organizes reading activities, for example, extracurricular reading in classroom at own initiative ("We have a classroom reading calendar to mark the books of the month to be read by children each month") (teacher 2), takes care of reading resources ("We buy books, make photocopies of texts") (teacher 4), encourages children "to also visit the e-library" (teacher 3). A classroom in a primary school must be packed with books (textbook author 1).

School-family collaboration. The experts have indicated that teachers only are not in the position to activate reading in children, and collaboration with the family and librarians is necessary to engage them in development of children's reading skills at primary school.

I prepare the parents at the second grade. I ask them to help, read to the child and listen to the child read (teacher 5).

We hold literary events, and parents are invited to attend together with the children. Children meet writers at these events, see a crown put on a writer's head, and receive the writer's autograph (teacher 8).

Reading environment in family and at home. When analysed as a feature of social interaction at school and in family, book reading shows clear tendency of being a collective activity of a child and parent. In this case, a child would read only when observing adults read, when they talk to the child about what they read. One expert of primary education has emphasized that, if " $a$ child and mother read the same book, discussions on the text take place" (teacher 2).

If parents read, if they are educated people, the child also reads, and a book carries value to them (teacher 9).

Moreover, the experts have emphasized that they conduct preparatory activities with parents as well: "Sometimes parents must be encouraged to read to children (teacher 8), as there are families, where parents do not read and do not have any reading resources. The expert has argued that the initiative of promotion of reading fails completely in the family, as "family situation plays a considerable role here". Home reading resources are an important factor of promotion of reading. If a child is not provided with a proper reading environment at home, he/she simply does not read. The experts have identified an important social factor - parents' financial resources that limit the possibilities for children to access the cultural resources.

If parents buy books, are interested in books, visit book stores, the children also like being in book stores (teacher 4).

Children do not bring books to school, because they do not have them at home, and they do not have the books, because they are expensive" (teacher 9).

Content of reading material: avoidance of social and emotional tensions, conflicts of social reality in texts. The experts have emphasized the following main issues related to the reading tools: quality of the text content and insufficient diversity of texts. Such situation is determined by the institutional 
control of teaching materials and aids for reading. Texts are overpolished: texts on the phenomena of social reality - social exclusion, disability, violence - are subject to expert review. Critical, painful parts of texts are simply taken out, and polished, fragmented texts lacking the key idea, with the authorship difficult to recognize (if the authorship was not indicated) are used in the textbooks.

You read poems by the classic poets and see that nothing has been left.Three stanzas have been published, while the forth has been take out as inappropriate for the age group (publisher).

We added an excerpt from story "Drambliene" (She-Elephant) by E.Liegute telling of a child's mother who was alcoholic and took the shoes from the child, so the child came to school in old shoes stuffed with hay. The experts took the text out. There is a saying used in the folklore: "galvageniuičekšt" (cut the head of the woodpecker), they took it out as well. An excerpt was inserted telling about a mother who took money from the father and gave it to the child. So, we were accused of teaching children to steal. We are now afraid of such things (textbook author 1).

A gypsy was mentioned - my God! Just a single mention of another nationality, and the text is not accepted. You are not supposed to say that someone is disabled - you may draw only, so I drew him, as such texts had not passed (textbook author 2).

One of the experts has shared her international experience related to the Swedish textbook texts: "the Swedish use texts telling children of a hysterical mother who shouts at her child - they do not fear such texts" (publisher). The experts have admitted that "we also need such texts - we did use them, but the expert reviewers took them out"(textbook author). Moreover, one expert has emphasized that the texts presented in textbooks are fragmented: "Only six pages of the best works, for example, by A. Lindgren, are used" (teacher 12).

The experts have been asked about reading methods, about how a child is taught to read. One expert has noted that, at first, reading technique is taught: "We teach reading technique at the first, second grade" (teacher 6). According to another expert, reading under proper technique is necessary, as, otherwise, reading "does not lead deeper into the text, and children read mechanically" (teacher 2). It must be noted that reading mechanically is still widespread at schools: "Children sit in the classroom and perform mechanical action, with nothing in their eyes. Here you go - I've written the analysis, but there is no child in the analysis (textbook author 1), while "a child wants to feel into the topic, but has no time to go deeper into the texts, as there is an insane amount of texts, and the children are simply overloaded" (teacher 12).

Reading resources and reading tools at school could be named as the key causes of development of reading skills. Reading mechanically, as opposed to meaningful reading, delays successful interaction during the process of reading that implies going deeper into the text, its discussion and sharing of own experience by the reader. 


\section{Conclusions}

Conceptual frameworkof cultural capital has allowed actualising the importance of sociocultural and socioeconomic factors in family and at school for the child's reading. The performed theoretical analysis reveals that development of children's reading skills is complex for several reasons: first, due to the cultural environment, cultural activity, and cultural objects in family; second, due to the processes of development of reading skills at school/in the classroom. The third reason is social interaction between the family and school. Interaction between family and school increases the possibilities for the child to acquire and integrate knowledge.

Two-fold approach towards reading may be taken. First, reading is the means to develop own language, literary and cultural knowledge, better comprehension of the read texts. Second, reading is a social indicator that forms a child's cultural capital on the basis of reading activity. Studies on reading and cultural capital reveal the aspect of linkage between themand their interdependence. Child's cultural capital is reproduced into reading skills. There fore, a child's reading abilities and formation of cultural capital are based on two states: reading activity and material cultural resources. The factor of education (e.g. parents' education) has not been analysed in this article. Culture is reproduced bythe embodied state of family's cultural capital formed by cultural activities and the available cultural objects (objectified state of cultural capital). The research results have suggested that the embodied state and the material state (cultural resources) are important for development of reading abilities in a child.

The experts have noted that collective reading activity involving adults and children, when children become engaged in the reading process, forms children's cultural capital and develops their reading skills. Child's reading skills are related to home reading activity and books available at home. Later, as the child starts attending school, teachers' reading activities and reading objects at school become important for development of reading skills.Uninterrupted library funding, professional librarians and diversity of books are necessary for formation of child's cultural capital. Librarians are highly important for the children who do not have any books at home.Analysis of the links between children's reading abilities and social factors has revealed that children's reading skills are, to the greatest extent, related to sociocultural environment in the family, i.e. the available books at home and cultural activity.

\section{References}

Blumer, H. (1969). Society as Symbolic Interaction. In Arnold Rose (Ed.). Human Behavior and Social Processes. Boston: Houghton Mifflin.

Bourdieu, P. (1986). The Forms of Capital. The Handbook for Theory and Research forthe Sociology of Education. John G. Richardson (Ed.). Greenwood Publishing Group. Pp. 241-58. 


\section{SOCIETY. INTEGRATION. EDUCATION. Volume II}

Bourdieu, P. (1990). The Logic of Practice. Cambridge: Polity Press.

Bourdieu, P. and Passeron, J-C. (1990). Reproduction in Education, Society and Culture. London: Sage. Cambridge: Harvard University Press. Pp. 272.

Burgess, S. R. (2002). The influence of speech perception, oral language ability, the home literacy environment, and pre-reading knowledge on the growth of phonological sensitivity: A one-year longitudinal investigation. Reading and Writing, 15. Pp. 709737.

Flick, U. (2014). An introduction to Qualitative research. Pp. 227.

Katsillis, J. and Rubinson, R. (1990). Cultural Capital, Student Achievement and Educational Reproduction: The Case of Greece. American Sociological Review, 55. pp. 270-279.

Leonavičius, V., Norkus Z., Tereškinas, A. (2005). Socialinio konflikto teorijos. Socialinès teorijos. Pp. 220.

Ruddell, R. (2005). Teaching children to read and write: Becoming an effective literacy teacher. Boston: Allyn\& Bacon.

Sullivan, A. (2001). Cultural Capital and Educational Attainment. Sociology, 35 (4). Pp. 893 912.

Walczyk, J.J., Griffith-Ross, D.A. (2007). How important is reading skill fluency for comprehension? The Reading Teacher, 60. Pp. 560-569. 